\title{
BMJ Open Print and online newspaper coverage of the link between HPV and oral cancer in the UK: a mixed-methods study
}

\author{
Rachael H Dodd, Laura A V Marlow, Alice S Forster, Jo Waller
}

To cite: Dodd $\mathrm{RH}$,

Marlow LAV, Forster AS, et al. Print and online newspaper coverage of the link between HPV and oral cancer in the UK: a mixed-methods study. BMJ Open 2016;6:e008740. doi:10.1136/bmjopen-2015008740

- Prepublication history for this paper is available online. To view these files please visit the journal online (http://dx.doi.org/10.1136/ bmjopen-2015-008740).

Received 11 May 2015 Revised 17 December 2015 Accepted 9 February 2016

CrossMark

Department of Epidemiology \& Public Health, Cancer Research UK Health Behaviour Research Centre, UCL, London, UK

Correspondence to Rachael H Dodd; r.dodd@ucl.ac.uk

\section{ABSTRACT}

Objectives: The role of human papillomavirus (HPV) in some oral cancers has been reported in the news press, though little is known about the content of these articles. This study aimed to examine how frequently the link between HPV and oral cancer has been reported in the news press and to examine the content of these articles.

Design: UK media articles were searched for articles relating to oral cancer and HPV in the database NexisUK. Of 854 articles identified by the initial search, 112 were eligible for inclusion (2002-2014) and content analysis was used to determine the main themes discussed.

Results: Themes included actor Michael Douglas' claim that his throat cancer was caused by HPV, the riskiness of oral sex, health information (including HPV as a cause of oral cancer) and the need to vaccinate boys against HPV. Many articles also referred to the link between HPV and cervical cancer and the increasing incidence of HPV-related oral cancer. The largest peak in articles occurred when Michael Douglas discussed his cancer (June 2013). Facts about HPV and references to research were provided in some articles.

Conclusions: The link between HPV and oral cancer and the transmission of HPV via oral sex was regularly discussed, yet coverage often lacked detailed health information. This could increase awareness of the link between oral sex and HPV risk, but may also lead to public concern about oral sex as a sexual behaviour.

\section{INTRODUCTION}

Traditional risk factors for oral cancer are tobacco and alcohol, but there is now overwhelming evidence that human papillomavirus (HPV) plays a causal role in some types of the disease. ${ }^{1-4}$ At least $25 \%$ of the estimated 85000 oropharyngeal cancers diagnosed worldwide in 2008 were HPV-positive. ${ }^{5}$ HPV is a common sexually transmitted infection, with high-risk types shown to be responsible for up to $5 \%$ of all cancers worldwide, particularly cervical and other anogenital cancers. ${ }^{6}$ The main risk factors for

\section{Strengths and limitations of this study}

- This is the first study to examine the content of newspaper articles addressing the relationship between human papillomavirus (HPV) and some oral cancers.

- Using NexisUK to examine UK media coverage of the link between HPV and oral cancer provides a systematic analysis of a large number of publications.

- This study is limited to UK publications and to print and online media, so the results may not be representative of wider information available to the public.

- The articles in the study were only examined for content and not for accuracy of the information presented.

transmission of HPV are thought to be a greater number of sexual and (for oral infection) oral sex partners ${ }^{7-10}$ due to greater exposure to the virus.

Prior to the introduction of the HPV vaccination in 2008, public awareness of HPV (primarily in the context of cervical cancer) was measured in population-based studies to be between $25 \%$ and $50 \% .{ }^{11} 12$ The HPV vaccination attracted a lot of media attention ${ }^{13}$ and knowledge of HPV appears to have increased following its introduction. ${ }^{14}$ In an online survey across the UK, USA and Australia following the introduction of the HPV vaccine, $39 \%$ of men and $62 \%$ of women in the UK reported having heard of HPV. ${ }^{15}$

In the oral cancer context, no UK studies have yet examined knowledge that HPV is a risk factor for oral cancer. In the USA, dental hygienists in North Carolina were found to have low knowledge of HPV as a risk factor for oral cancer compared with tobacco and alcohol. ${ }^{16}$ In a USA populationbased online survey, HPV was recognised as a common risk factor for mouth and throat cancer by fewer than $1 \%$ of participants, and even when prompted explicitly about the link, just $13 \%$ said they had heard of 
the association. ${ }^{17}$ In an internet survey of men, a greater proportion linked HPV with genital warts than with oral cancer, with $43 \%$ identifying infection with HPV as a potential cause of oral cancer. ${ }^{18}$ Public awareness of the signs and risk factors for head and neck cancer has also been shown to be poor ${ }^{19-21}$ and the majority of oral cancers are diagnosed at an advanced stage. ${ }^{22}$

As the media has been shown to influence people's beliefs $^{23}$ and is considered a major source of health information for many, ${ }^{24}$ it is possible that media coverage of the link between HPV and oral cancer may influence public awareness and perceptions. The British media is no stranger to reporting stories about people in the public eye with cancer, most notably the stories of Jade Goody (an English reality television personality), Kylie Minogue (an Australian singer/songwriter) and Angelina Jolie (an American actress). Metcalfe et $a l^{25}$ reported that an increased public interest in disease prevention can follow a celebrity diagnosis. In the UK, the case of Jade Goody (who died of cervical cancer) was associated with an increase in the number of women attending cervical screening. ${ }^{26}$ In 2013, American actor Michael Douglas disclosed in an interview with The Guardian newspaper that his throat cancer was 'caused by HPV which actually comes about from cunnilingus'. This disclosure received global attention, giving the media an opportunity to discuss the link between HPV and oral cancer. However, media reports are sometimes criticised for the lack of detail they provide, for example, with the announcement of Angelina Jolie's double mastectomy many failed to give information about the rarity of her condition. ${ }^{27}$

Media priming may be used to strengthen the association between a person's existing beliefs and their subsequent behaviour by making these beliefs more accessible. ${ }^{28}$ Mass media campaigns for cancers such as breast and lung (eg, the Cancer Research UK Be Clear on Cancer campaign) have been shown to be effective in increasing awareness of key symptoms for these cancers and increases in general practitioner attendance. $^{29}$ As this shows, media coverage is one route through which public understanding of health issues might be improved, but little is known about British media coverage of the link between HPV and oral cancer. The media has been shown to be a common source of information about HPV $^{12}$ and greatly influences public opinion, and as such it is crucial to examine how the link is portrayed by the British media. As the media may play an important role in fulfilling the information needs of the public, examining the content of articles will establish what information is being conveyed and how this is communicated. This study aimed to examine how frequently the link between HPV and oral cancer has been reported in the news press and whether this has changed over time. The study also aimed to examine the content of the articles, in particular looking at the main topics reported and how the link between HPV and oral cancer has been presented.

\section{METHODS}

The NexisUK database was used to search for print and online articles in the UK relating to HPV and oral cancer. NexisUK is an online database providing full-text access to international, national and regional news sources, and is updated daily. The search was conducted on the 20 August 2014 with no date limits applied. The search terms 'oral cancer', 'mouth cancer', 'throat cancer', 'oropharyngeal cancer', 'head and neck cancer' were entered into the database separately, limited to major mentions (in the headline, lead paragraph or indexing) and combined with (HPV OR human papillomavirus) within UK publications. Newswire and nonbusiness news publications (eg, obituaries, sports) were not searched. The full text of each publication was reviewed by RHD. Newspaper articles were categorised using Newsworks ${ }^{30}$ as 'broadsheet' newspapers (more intellectual in content eg, The Guardian, The Times), 'middle market' newspapers (coverage of entertainment and important news stories eg, Sunday Express, London Evening Standard) and 'tabloid newspapers' (reporting mostly on sensational material, eg, The Sun, Kidderminster Shuttle). Regional newspapers were categorised by discussion.

\section{Quantitative analysis-frequency of articles}

The frequency of reporting of the link between HPV and oral cancer was analysed using a frequency count. The number of articles per month reporting the link was plotted from the first publication to the most recent publication.

\section{Qualitative analysis-content of the articles}

The headlines of all articles were analysed descriptively. The content of eligible articles was analysed using Framework Analysis. ${ }^{31}$ RHD first familiarised herself with the content by reading through all the eligible articles, making notes of recurring themes and summarising each article. Using the qualitative package NVivo V.10, a list of codes was generated from the data and these codes were applied to the data. The data were summarised and organised into a matrix of main themes and subthemes, with each row representing an article and each column representing a theme/subtheme. ASF coded $20 \%$ of the articles to test inter-rater reliability. Second coding of $20 \%$ of the articles has been considered sufficient in similar studies. ${ }^{32}{ }^{33}$ Cohen's $\kappa$ across all themes was 0.71 representing a substantial agreement. $^{34} 35$ Table 1 shows Cohen's $\kappa$ for each main theme and subthemes. Any disagreements were resolved by discussion and the remaining articles were coded by RHD alone. Short quotations illustrating each theme are presented in the text, and additional quotes are presented 
Table 1 Main themes and subthemes with inter-rater reliability

\begin{tabular}{|c|c|c|}
\hline Theme & (Cohen's k) & Description of theme \\
\hline Michael Douglas' disclosure & $(0.67)$ & $\begin{array}{l}\text { The disclosure from Michael Douglas that his throat cancer was } \\
\text { caused by HPV }\end{array}$ \\
\hline Health information & $(0.70)$ & Represents information communicated about HPV and oral \\
\hline A. HPV as cause of oral cancer & $(0.73)$ & cancer related to health. The subthemes represent specific health \\
\hline B. Incidence of oral cancer & $(0.61)$ & information given about HPV and oral cancer \\
\hline C. Information about HPV & $(0.62)$ & \\
\hline 1. Cause of cervical cancer & & \\
\hline 2. How common HPV is & & \\
\hline 3. Number of different types of HPV & & \\
\hline 4. Demographic changes & & \\
\hline D. Better prognosis and survival & $(0.79)$ & \\
\hline E. Diagnosis and treatment for oral cancer & $(0.77)$ & \\
\hline F. Symptoms and screening for oral cancer & $(0.56)$ & \\
\hline G. Cited research evidence & $(0.69)$ & \\
\hline Riskiness of oral sex & $(0.77)$ & $\begin{array}{l}\text { Represents information communicated about the recognition of } \\
\text { oral sex in the cause of oral cancer and how changes in sexual } \\
\text { practice are thought to account for this }\end{array}$ \\
\hline Vaccination of boys & $(0.85)$ & $\begin{array}{l}\text { Represents the calls for boys to be vaccinated in light of the } \\
\text { evidence that HPV does not only cause oral cancer, but other } \\
\text { cancers as well }\end{array}$ \\
\hline
\end{tabular}

in table 2, along with the publication title, date published and quotation number.

\section{RESULTS}

\section{Article characteristics}

A total of $854 \mathrm{UK}$ articles were identified. Articles were excluded if they were (1) duplicates (articles published around the same time, with the same number of words in the same publication and duplicating text) $(\mathrm{n}=477)$; (2) were published in a specialist magazine or publication $(n=80)$; or (3) did not mention the link between oral cancer and HPV $(n=32)$. Following these exclusions, 265 articles were eligible for inclusion in the quantitative analysis. An additional 153 articles were excluded from the qualitative analysis because they included fewer than 100 words about the link between oral cancer and HPV. These articles tended to include a sentence about the link between HPV and oral cancer as part of a story with a different focus; they did not have sufficient text to merit qualitative analysis. Overall 112 articles were suitable for the qualitative analysis.

The newspapers with the greatest number of articles eligible for qualitative analysis were The Times $(n=16)$, MailOnline $(n=10)$, The Guardian $(n=8)$ and The Independent $(n=9)$. Broadsheet newspapers accounted for $54 \%$ of the articles, $21 \%$ were from middle market newspapers and $25 \%$ were from tabloid newspapers. With regard to average length, broadsheet articles tended to be longer ( 530 words average), followed by those in middle market newspapers (472 words average), with tabloid newspapers having the shortest
(458 words average) articles. A fairly small proportion of articles $(18 / 112 ; 16 \%)$ were published in regional papers.

\section{Quantitative analysis-frequency of articles}

No UK publications reported the link between HPV and oral cancer prior to 2001. Figure 1 shows the frequency of articles published per month mentioning the link between HPV and oral cancer. There was a steady number of articles reporting on the link, but for most years, on average, fewer than two articles were published per month across the newspapers. The largest number of articles reporting on the link between HPV and oral cancer was seen in 2013 (112/265). Broadsheet newspapers first reported that there was a link between HPV and oral cancer in October 2001, followed by tabloid newspapers in February 2004 and middle market newspapers in November 2009.

There was a noticeable peak in June 2013 (45/265) with $34 / 45$ of these discussing Michael Douglas' throat cancer being caused by HPV. There were a few small peaks in articles published in May 2007 (6/265), with $5 / 6$ discussing a research paper which further demonstrated the link between oral sex and throat cancer, ${ }^{7}$ in March 2012 (7/265) reflecting the publication of figures demonstrating a rise in mouth cancers, and in November 2013 (16/265) with 10/16 articles reflecting on mouth cancer awareness month.

\section{Qualitative analysis-content of the articles Headlines}

About one-third (35/112) of the headlines mentioned oral sex (eg, 'Oral sex can lead to mouth cancer' 
Table 2 Quotes from themes and subthemes

\section{Quote (Q) number}

Quotes

$1 \quad$ 'Michael Douglas did not say cunnilingus was the cause of his cancer. It was discussed that oral sex is a suspected cause of certain oral cancers...but he did not say it was the specific cause of his personal cancer.' 'Even with statements from his publicist denying he had put the blame on oral sex specifically, this genie is not going back in the bottle. And perhaps that's a good thing.' 'Oral sex can lead to mouth cancer, according to new research.'
'What is most strongly linked to oral HPV infection is the number of sexual partners someone has had in their lifetimes, in particular the number of individuals on whom they have performed oral sex.'

'A US study showed about 10 per cent of men aged 14 to 69 have an oral HPV infection, compared with 3.6 per cent of women.

Because HPV-related oral cancer is twice as common in men as in women, cunnilingus is considered riskier than fellatio.'

'Without wanting to get too specific, this particular cancer is caused by HPV, which actually comes about from cunnilingus...But yeah, it's a sexually transmitted disease that causes cancer. And if you have it, cunnilingus is also the best cure for it.'

'If you have an ulcer that doesn't heal after three weeks, see your dentist or doctor.'

'Just a few strains cause problems, but one in particular, HPV-16, is known to cause cell changes which could develop into cancer.' 'Given that subgroups of people with HPV-related H\&N [head and neck] cancers display excellent survival, these patients may in future be offered less aggressive treatment...'

'Men are advised to check their neck for lumps when shaving and both sexes to look at the back of their throat while brushing their teeth.'

'HPV is really, really common-to the point that if you're a sexually active adult, you've probably had it. By the age of $25,90 \%$ of sexually active people will have been exposed to some form of genital HPV.'

'Increased recovery rates among this kind of cancer sufferer. This would help explain why Douglas was given an $80 \%$ chance of survival, despite the advanced stage of his illness.'

'In Britain, the number of mouth and throat cancers have increased by 40 per cent in just a decade.'

'Treatments such as chemotherapy, radiotherapy and surgery are often more successful in mouth and throat cancers caused by the virus than those caused by tobacco and alcohol.'

'These striking results provide some evidence that HPV16 infection may be a significant cause of oropharyngeal cancer.'

'Mouth cancer survival rates of about $50 \%$ haven't changed in decades, but if the disease is caught early patients can have a $90 \%$ chance of a cure.'

Professor Maura Gillison-'The time has come to have a more thorough discussion about the potential benefits of HPV vaccines in boys ... When my patients ask whether they should vaccinate their sons [with the HPV vaccine], I say 'certainly'. The vaccine will protect them against genital warts and anal cancer and-as a potential by-product of that-it may protect them against oral cancer caused by HPV ... The time has come to consider offering the HPV vaccine to boys.'

Themes

Newspaper information

Michael Douglas'

disclosure

MailOnline, 4

June 2013

Michael Douglas'

disclosure

Riskiness of oral sex

Riskiness of oral sex

Riskiness of oral sex

Riskiness of oral sex

Health information: symptoms

Health information: information about HPV Health information:

diagnosis and

treatment

Health information:

symptoms

Health information: the high prevalence of HPV

Health information: better prognosis and survival

Health information: the incidence of oral

cancer

Health information:

better prognosis and survival

Health information:

HPV causes oral

cancer

Health information:

diagnosis and

treatment

HPV vaccination for boys
The Telegraph, 4 June 2013

Birmingham Post, 26 February 2004 The Guardian, 21 February 2011

London Evening Standard, 4 June 2013

The Times, 5 June 2013

Daily Mirror, 28 March 2008 MailOnline, 16 March 2012 The Western Mail, 25 February 2013

MailOnline, 13 November 2013

The Guardian, 2 June 2013

The Guardian, 2 June 2013

MailOnline, 3 June 2013

MailOnline, 16 July 2013

The Times, 26 July 2013

Daily Mirror, 28 February 2014

The Independent, 21 February 2011 
Table 2 Continued

\begin{tabular}{|c|c|c|c|}
\hline $\begin{array}{l}\text { Quote (Q) } \\
\text { number }\end{array}$ & Quotes & Themes & $\begin{array}{l}\text { Newspaper } \\
\text { information }\end{array}$ \\
\hline 18 & $\begin{array}{l}\text { Professor Margaret Stanley - 'it is not ethical, fair or socially } \\
\text { responsible to have a public-health policy that forces men to rely on } \\
\text { herd immunity, which won't be reached for decades.' }\end{array}$ & $\begin{array}{l}\text { HPV vaccination for } \\
\text { boys }\end{array}$ & $\begin{array}{l}\text { MailOnline, } 3 \\
\text { June } 2013\end{array}$ \\
\hline 19 & $\begin{array}{l}\text { 'We [Department of Health] recognise that the current vaccination } \\
\text { programme does not offer protection against HPV-related cancers } \\
\text { for gay men.' }\end{array}$ & $\begin{array}{l}\text { HPV vaccination for } \\
\text { boys }\end{array}$ & $\begin{array}{l}\text { The Independent, } \\
2 \text { February } 2014\end{array}$ \\
\hline 20 & $\begin{array}{l}\text { 'Campaigners are calling for boys to have the jab too in order to } \\
\text { stem the "catastrophic rise" in cancers.' }\end{array}$ & $\begin{array}{l}\text { HPV vaccination for } \\
\text { boys }\end{array}$ & $\begin{array}{l}\text { Daily Mirror, } 28 \\
\text { February } 2014\end{array}$ \\
\hline
\end{tabular}

Birmingham Post, 26 February 2004) and Michael Douglas was mentioned in a quarter (28/112) of the headlines (eg, 'Michael Douglas says cunnilingus gives you cancer but is he right?' The Guardian, 2 June 2013). 'Throat cancer' was the most frequently used term for the disease, mostly reflecting the terminology used by Douglas himself, with 'mouth cancer' and 'oral cancer' also used. Some headlines $(33 / 112 ; 29 \%)$ emphasised the risk of oral sex and cancer (eg, 'Mouth cancer rise in young people is linked to oral sex' The Metro, 16 March 2012), and some used the words 'risk', 'alert' and 'dangers' when referring to the link between HPV and oral cancer:

Your life: Oral Sex cancer risk. (Daily Mirror, 28 March 2010)

Early alert for throat cancer. (The Times, 22 July 2013)

Stay alive to the dangers of mouth cancer. (Kidderminster Shuttle, 6 November 2010)
Others emphasised the sexual nature of the link using terms like 'sex virus', 'will oral sex ever feel safe again' and 'struck a blow for oral sex'.

\section{Article content}

Four main themes emerged from the content analysis of the reviewed articles: Michael Douglas' disclosure, the riskiness of oral sex, health information communicated about HPV, including HPV as a cause of oral cancer and its incidence, and the need to vaccinate boys against HPV.

\section{Michael Douglas' disclosure}

In June 2013, Michael Douglas revealed that HPV was responsible for his throat cancer and that it was transmitted through oral sex. This disclosure was more commonly reported in broadsheet newspapers. There was a peak in the number of articles covering this link (34/112;30\%) in June 2013, including those which reported on Michael

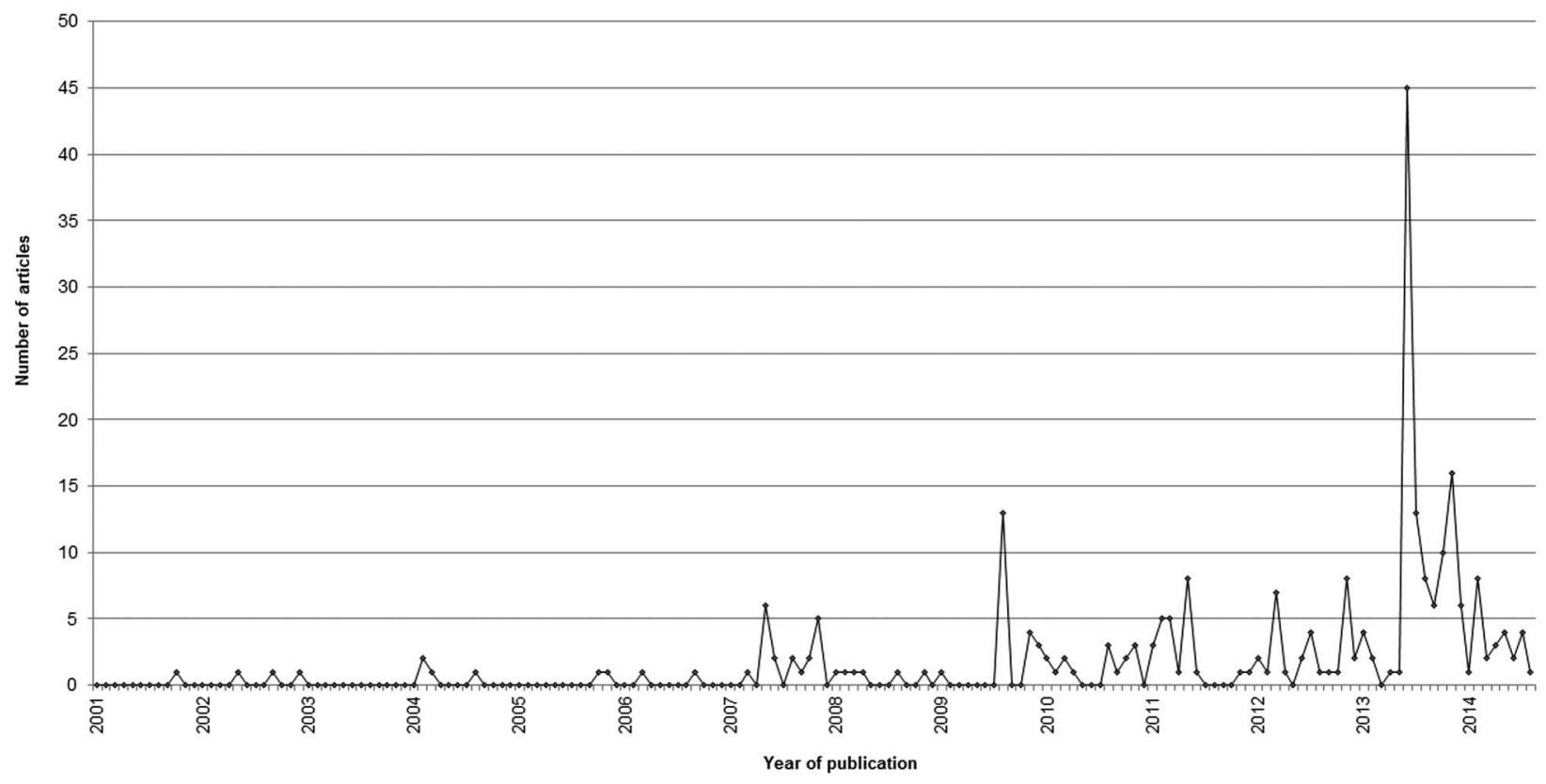

Figure 1 The number of UK media articles reporting on the link between oral cancer and human papillomavirus from 2001 to 2014. 
Douglas' subsequent assertion that he was talking about causes of oral cancer more generally, rather than being specific to him (MailOnline, 4 June 2013, Q1).

There were suggestions in some of the articles that Michael Douglas had raised awareness of the link between HPV and oral cancer and had 'broken the last taboo for men' by raising the topic of oral sex (The Telegraph, 4 June 2013, Q2).

\section{Riskiness of oral sex}

A large number $(83 / 112 ; 74 \%)$ of the articles mentioned oral sex as a cause of mouth cancer (Birmingham Post, 26 February 2004, Q3).

HPV was mentioned as being transmitted through oral sex, with articles quoting Michael Douglas including the term 'cunnilingus' and stating that HPV is a sexually transmitted disease (The Times, 5 June 2013, Q6).

This disclosure from Michael Douglas led some articles to discuss the risk of different sexual behaviours, for example, 'Is cunnilingus inherently riskier than fellatio?' (The Guardian, 2 June 2013) with a number of these providing research findings (London Evening Standard, 4 June 2013, Q5).

Some articles $(14 / 112 ; 13 \%)$ expressed the belief that the rise in throat cancer was due to changes in sexual practice: 'the rise in HPV-related throat cancer is being seen as the legacy of the sexual revolution that began in the 1960s' (The Independent, 21 January 2012), with an increase in oral sex practices leading to increases in oral HPV and therefore throat cancer (The Guardian, 21 February 2011, Q4).

The link between oral sex and mouth cancer was not as clear cut, according to Cancer Research UK quoted to have said 'it was unclear if it was linked with oral sex' (The Independent, 16 March 2012). A few (5/112; 4\%) of the articles suggested that HPV transmitted through oral sex 'could overtake tobacco and alcohol as the main risk factor in the next decade' (Western Morning News, 23 November 2010).

It was also acknowledged that 'oral sex is a topic which could not have been discussed openly even recently' (The Telegraph, 4 June 2013).

One article asked 'should oral sex be off the agenda' (Daily Mirror, 28 February 2014), with other articles terming oral sex as 'now officially life-threatening' (The Times, 26 May 2007) and that HPV is a 'devastating virus' (The Sun, 13 February 2014).

\section{Health information}

Most of the articles providing health information focused on the link between HPV and oral cancer. Table 3 shows what health information was presented in each type of publication. The different types of information are discussed below.

HPV causes oral cancer: As mentioning the link between HPV and oral cancer was an inclusion criteria, all articles included this, with the majority $(88 / 112 ; 79 \%)$ of the articles mentioning the link between HPV and oral cancer within the first 100 words. The terms used were inconsistent, with mouth cancer, oral cancer and throat cancer used interchangeably. Some articles were more specific about the type of cancer caused (The Times, 26 July 2013, Q15).

The incidence of oral cancer. In total, 61/112 (54\%) articles reported on the incidence of oral cancer, with 57/ $112(51 \%)$ reporting that the number of cases was increasing. One newspaper quoted a Cancer Research UK expert as describing 'an emerging epidemic' (in oral cancer) and 5/112 (4\%) quoted Cancer Research UK as linking the HPV virus to the 'rapid rise' (in oral cancer cases; MailOnline, 3 June 2013, Q13).

A change in the demographic characteristics of those being diagnosed with oral cancer was also mentioned in a number of the articles $(49 / 112 ; 44 \%)$, emphasising

Table 3 Themes mentioned in articles across the publication types

\begin{tabular}{|c|c|c|c|c|}
\hline \multirow[b]{2}{*}{ Theme } & \multicolumn{4}{|c|}{ Number of articles including each theme } \\
\hline & $\begin{array}{l}\text { All publications } \\
(n=112)\end{array}$ & $\begin{array}{l}\text { Broadsheet } \\
(n=61)\end{array}$ & $\begin{array}{l}\text { Middle market } \\
(n=23)\end{array}$ & $\begin{array}{l}\text { Tabloid } \\
(n=28)\end{array}$ \\
\hline $\begin{array}{l}\text { Michael Douglas' disclosure } \\
\text { Health information }\end{array}$ & $50(45 \%)$ & $25(41 \%)$ & $14(61 \%)$ & $11(39 \%)$ \\
\hline Link oral cancer and HPV & $112(100 \%)$ & $61(100 \%)$ & $23(100 \%)$ & $28(100 \%)$ \\
\hline Incidence of oral cancer & $61(54 \%)$ & $29(48 \%)$ & $13(57 \%)$ & $19(68 \%)$ \\
\hline \multicolumn{5}{|l|}{ Information about HPV } \\
\hline Cause of cervical cancer & $63(56 \%)$ & $33(54 \%)$ & $12(52 \%)$ & $18(64 \%)$ \\
\hline 100 variants of HPV & $11(10 \%)$ & $5(8 \%)$ & $3(13 \%)$ & $3(11 \%)$ \\
\hline 8/10 will contract HPV & $12(11 \%)$ & $5(8 \%)$ & $3(13 \%)$ & $4(14 \%)$ \\
\hline $90 \%$ will contract HPV by age 25 & $6(5 \%)$ & $6(10 \%)$ & 0 & 0 \\
\hline Better prognosis and survival & $18(16 \%)$ & $4(7 \%)$ & $10(43 \%)$ & $4(14 \%)$ \\
\hline Diagnosis and treatment & $29(26 \%)$ & $10(16 \%)$ & $10(43 \%)$ & $9(32 \%)$ \\
\hline Symptoms and screening & $36(32 \%)$ & $15(25 \%)$ & $10(43 \%)$ & $11(39 \%)$ \\
\hline Riskiness of oral sex & $83(74 \%)$ & $42(69 \%)$ & $20(87 \%)$ & $21(75 \%)$ \\
\hline Vaccination of boys & $40(36 \%)$ & $22(36 \%)$ & $6(26 \%)$ & $12(43 \%)$ \\
\hline
\end{tabular}


that patients are increasingly younger, male, nonsmokers and from professional backgrounds. A few $(9 / 112 ; 8 \%)$ articles also suggested that there was a shift towards more women getting oral cancer.

Information about HPV: Over half of the articles also mentioned HPV as a cause of cervical cancer (63/112; $56 \%)$ and presented information about there being 'more than 100 variants' of HPV. In total, 19/112 (17\%) articles highlighted that not all types of HPV cause cancer (MailOnline, 16 March 2012, Q8).

The high prevalence of HPV: In 30/112 (27\%) articles, it was mentioned that most people will be infected with HPV at some point (The Guardian, 2 June 2013, Q11).

A total of 16/112 (14\%) articles expressed the need for increased awareness of the link between HPV and oral cancer, for example, 'few people can recognise its symptoms' (Kidderminster Shuttle, 6 November 2010). Nigel Carter, Chief Executive of the British Dental Health Foundation was quoted as saying, 'there is a clear gap in public knowledge about what causes mouth cancer' (Daily Mirror, 28 February 2014).

Better prognosis and survival: The positive prognosis and survival rates of HPV-related oral cancer were discussed $(18 / 112 ; 16 \%)$, sometimes in the context of Michael Douglas' own survival (The Guardian, 2 June 2013, Q12).

Survival was also discussed in comparison to oral cancers without HPV as a cause (MailOnline, 16 July 2013, Q14).

Diagnosis and treatment: Early diagnosis of oral cancer was mentioned as giving a 'better chance of successful treatment' (Daily Mirror, 28 February 2014, Q16) by 14/ $112(13 \%)$ articles.

Treatment methods, particularly chemotherapy and radiotherapy were mentioned, as well as the possibility for less invasive treatment in the future (The Western Mail, 25 February 2013, Q9).

Symptoms: Symptoms of oral cancer were reported more frequently in tabloids and middle market newspapers than in broadsheets (Daily Mirror, 28 March 2008, Q7).

The importance of dentists was emphasised, explaining that they play a vital role in oral cancer diagnosis as well as doctors. Advice was given as a slogan, 'If in doubt, get checked out' and ways to look for symptoms of oral cancer were suggested (MailOnline, 13 November 2013, Q10).

Case studies were also included and often illustrated the symptoms of HPV-related oral cancer, the invasive and challenging treatment involved, and the importance of regular dental check-ups.

Cited research: Fewer than half $(42 / 112 ; 38 \%)$ referred to research findings from peer-reviewed journals. Research that was cited included studies showing the increase in incidence and burden of HPV-related oral cancer, showing evidence for patients with oropharyngeal cancer carrying antibodies to the E6 protein from the HPV16 virus ${ }^{36}$ and evidence for number of oral sex partners as a risk factor for HPV. ${ }^{7}$

\section{HPV vaccination for boys}

The link between oral sex and oral cancer was given as a strong reason for boys to be vaccinated against HPV. HPV Action, a group campaigning for the vaccination of boys, was mentioned in three articles. Many of the articles covering news of campaigns to vaccinate boys spoke of the opportunity for the vaccine to reduce the number of oral cancer cases in men, calling for it to be 'a gender neutral vaccination' (Daily Mirror, 28 February 2014, Q20).

Arguments were made about the cost-effectiveness of introducing the vaccine for boys $(5 / 112 ; 4 \%)$ and that 'the Government could save thousands of lives and hundreds of millions of pounds for the NHS by vaccinating boys against a cancer-causing virus at a cost of around $£ 20 \mathrm{~m}$ a year' (The Independent, 2 February 2014).

An argument for vaccinating boys against HPV was also made with reference to other countries as Professor John Ashton said, 'It makes sense to give teenage boys as well as girls the HPV vaccine, which is already happening in Australia' (The Guardian, 19 September 2013).

Men who have sex with men were also acknowledged as an unprotected group in a number of articles (7/112 (6\%); The Independent, 2 February 2014, Q19).

It was acknowledged that the HPV vaccination would have to be repositioned, as parents currently know it as 'the cervical cancer vaccine'. There was also recognition that oral cancer is not the only HPV-related cancer to affect boys and that the virus is linked to anal and penile cancers.

Experts were quoted as being in favour of HPV vaccination for boys, including Professor Maura Gillison, who published evidence of the link between HPV and oral cancer (The Independent, 21 February 2011, Q17; MailOnline, 3 June 2013, Q18).

Jamie Rae of The Throat Cancer Foundation and HPV Action, expressed the view that not vaccinating boys is 'inequitable-in fact, I'd say it's an infringement of human rights, for all boys' (The Independent, 2 February 2014) and it is 'a flawed and discriminatory policy' (The Herald (Glasgow), 12 June 2013), in the campaign to vaccinate boys against HPV.

\section{DISCUSSION}

This study is the first to analyse print and online newspaper coverage of the link between HPV and oral cancer in the UK. Coverage of the link between HPV and oral cancer has increased in response to major news stories. Articles reporting the link between HPV and oral cancer increased in March 2012 as figures showed oral cancer cases to be rising. Michael Douglas' disclosure in June 2013 sparked an increase in media interest as well as discussions about vaccinating boys. The main themes found to be reported in UK publications were Michael Douglas' disclosure, the riskiness of oral sex, health information including HPV as a cause of oral cancer and its incidence, and the need to vaccinate boys against HPV. 
All the articles tended to report similar content and the themes remained consistent across the types of publication (eg, broadsheet or tabloid), but how this was presented did differ across publication type. Broadsheets were the first type of publication to report on the link in October 2001, followed by tabloids in February 2004 and middle market in November 2009. Results from research were reported in fewer than half of the articles. Basic facts about HPV were not reported in all articles, indicating that the public does not always receive even basic information which could help relieve any anxieties.

Articles focusing on Michael Douglas' disclosure were more likely to appear in broadsheets than the other types of publication, which is probably due to the interview being conducted with a Guardian reporter. Previous research has suggested that events such as a celebrity cancer diagnosis can create news coverage substantial enough to influence health behaviours such as attending cancer screening. ${ }^{26}{ }^{37}$ Oral sex was said to be the cause of Michael Douglas' cancer in articles talking about his disclosure, but there were not many articles addressing what HPV is and the risk factors associated with it. There was a missed opportunity to educate the public as many articles did not discuss the signs and symptoms of oral cancer and what individuals should do if they find a symptom. Tabloid and middle market newspapers covered these more often than broadsheet newspapers, but only tabloid newspapers mentioned HPV in their coverage on Mouth Cancer Awareness Month, held in November every year. As different newspapers appeal to different reader demographics, it is important for communication of HPV and oral cancer to be consistent across all newspaper types to minimise inequalities in awareness and consequently health outcomes.

Many of the references to oral sex related to the transmission of HPV. Some of the articles placed emphasis on the risk of oral sex, reporting that those with HPV-related oral cancer are 'more likely to be connoisseurs of cunnilingus and fellatio'. These comments risk HPV-related oral cancer being seen as a sign of promiscuity and sensationalise it rather than including facts and presenting an HPV infection as common. This, in addition to the information on the rising incidence of HPV-related oral cancer, could lead the public to overestimate the prevalence of HPV-related oral cancer. In a study with health professionals, normalising HPV by emphasising its high prevalence and association with normal sexual behaviour was seen as a key message for patients, to try to minimise any possible negative psychological outcomes. ${ }^{38}$ This information is also important for the partners of those diagnosed; we found that some articles suggested Michael Douglas could have contracted HPV from his wife, Catherine Zeta-Jones, and could suggest that she was to blame.

As Michael Douglas affirmed that he was talking about causes of oral cancer more generally, rather than being specific to him, this could also cause stigma towards
HPV-related oral cancer, as the public may feel that he was ashamed to admit his throat cancer was caused by oral sex. There is also the concern that those who have been diagnosed with HPV-related oral cancer will feel stigmatised, so it is important that appropriate messages are being given about HPV to reduce the stigma associated with this sexually transmitted infection. ${ }^{39}$ Including case studies may help the public empathise with the person in the case study and reduce stigma. However, case studies reported in the articles were used to illustrate some of the symptoms for HPV-related oral cancer and how invasive and challenging the treatment can be. Endorsements from case studies where symptoms were noticed and highlighting good prognosis with early diagnosis may encourage the public to adopt health protective behaviours such as checking for lumps and attending the dentist regularly.

Articles which included reasons for vaccinating boys used case studies, Michael Douglas and research to support their campaigns. The media has been shown to increase knowledge of HPV after coverage of the introduction of the HPV vaccination. ${ }^{14}$ Media coverage of the campaigns and the connection to Michael Douglas' disclosure has the opportunity to raise awareness among parents and as all the articles took a positive stance towards vaccinating boys, this may influence parents' decisions about vaccinating their sons against HPV. Including endorsements from leading researchers in the field of HPV and oral cancer may have enhanced the credibility of messages in the articles and encourage parents to vaccinate their boys should they have the opportunity. Parents of boys will need to be able to communicate to their sons the link between HPV and sex, given that the vaccine is currently positioned as the 'cervical cancer vaccine'. The media could play a role in facilitating this.

This study is limited to UK publications and to print and online media, with broadcasts on television not examined, and so the results may not be representative of wider information available to the public. Different content may have been presented in television broadcasts which have not been picked up in this study. The articles in the study were only examined for content and not for accuracy of the information presented as this was not an aim of the study.

Examining responses to articles presenting the link between HPV and oral cancer through analysis of the discourse of online comments made on these articles would be an interesting area for future research. Coding the frequency of the stories in each article may also be useful to do in the future to understand which stories gain traction in the media. Assessing public knowledge about the link between HPV and oral cancer would also be useful, and an important first step towards raising public awareness and designing appropriate information for patients diagnosed with the disease.

In conclusion, this study is the first to show that the link between HPV and oral cancer has received coverage 
in the UK media, but an opportunity was missed to educate the public and influence health behaviours, through the disclosure of Michael Douglas. It is important for researchers not only to monitor media coverage of the link, but to work with journalists to ensure the content of articles is accurate and appropriate. Transmission of HPV via oral sex was regularly discussed along with the link between HPV and oral cancer, which could raise public anxieties about oral sex. It is therefore important for journalists to aim to minimise stigma and blame associated with these messages, normalising HPV and portraying it as associated with normal sexual behaviour.

Contributors RHD, LAVM and JW conceived of the study and participated in the design. RHD participated in the acquisition, analysis and interpretation of the data and drafting of the manuscript. ASF also participated in the analysis and interpretation of the data. All the authors participated in the critical revision of the manuscript and approved the final version.

Funding RHD is funded by a Medical Research Council Studentship.

Competing interests None declared.

Provenance and peer review Not commissioned; externally peer reviewed.

Data sharing No additional data are available.

Open Access This is an Open Access article distributed in accordance with the terms of the Creative Commons Attribution (CC BY 4.0) license, which permits others to distribute, remix, adapt and build upon this work, for commercial use, provided the original work is properly cited. See: http:// creativecommons.org/licenses/by/4.0/

\section{REFERENCES}

1. Rietbergen MM, Leemans CR, Bloemena E, et al. Increasing prevalence rates of HPV attributable oropharyngeal squamous cell carcinomas in the Netherlands as assessed by a validated test algorithm. Int J Cancer 2013;132:1565-71.

2. Gillison ML, Broutian T, Pickard RKL, et al. Prevalence of oral HPV infection in the United States, 2009-2010. JAMA 2012;307:693-703.

3. Mehanna H, Beech T, Nicholson T, et al. Prevalence of human papillomavirus in oropharyngeal and nonoropharyngeal head and neck cancer-systematic review and meta-analysis of trends by time and region. Head Neck 2013;35:747-55.

4. Näsman A, Attner P, Hammarstedt L, et al. Incidence of human papillomavirus (HPV) positive tonsillar carcinoma in Stockholm, Sweden: an epidemic of viral-induced carcinoma? Int J Cancer 2009;125:362-6.

5. de Martel C, Ferlay J, Franceschi S, et al. Global burden of cancers attributable to infections in 2008: a review and synthetic analysis. Lancet Oncol 2012;13:607-15.

6. Parkin DM, Bray F. Chapter 2: The burden of HPV-related cancers. Vaccine 2006;24(Suppl 3):S3/11-25.

7. D'Souza G, Kreimer AR, Viscidi R, et al. Case-control study of human papillomavirus and oropharyngeal cancer. $N$ Engl $\mathrm{J}$ Med 2007;356:1944-56.

8. Gillison ML, D'Souza G, Westra W, et al. Distinct risk factor profiles for human papillomavirus type 16-positive and human papillomavirus type 16-negative head and neck cancers. J Natl Cancer Inst 2008;100:407-20.

9. D'Souza G, Agrawal Y, Halpern J, et al. Oral sexual behaviors associated with prevalent oral human papillomavirus infection. $J$ Infect Dis 2009;199:1263-9.

10. Blomberg M, Nielsen A, Munk C, et al. Trends in head and neck cancer incidence in Denmark, 1978-2007: focus on human papillomavirus associated sites. Int J Cancer 2011;129:733-41.

11. Marlow LAV, Waller J, Wardle J. Public awareness that HPV is a risk factor for cervical cancer. Br J Cancer 2007;97:691-4.
12. Pitts M, Dyson S, Rosenthal D, et al. Knowledge and awareness of human papillomavirus (HPV): attitudes towards HPV vaccination among a representative sample of women in Victoria, Australia. Sex Health 2007;4:177-80.

13. Forster A, Wardle J, Stephenson J, et al. Passport to promiscuity or lifesaver: press coverage of HPV vaccination and risky sexual behavior. J Health Commun 2010;15:205-17.

14. Kelly BJ, Leader AE, Mittermaier DJ, et al. The HPV vaccine and the media: how has the topic been covered and what are the effects on knowledge about the virus and cervical cancer? Patient Educ Couns 2009;77:308-13.

15. Marlow LAV, Zimet GD, McCaffery KJ, et al. Knowledge of human papillomavirus (HPV) and HPV vaccination: an international comparison. Vaccine 2013;31:763-9.

16. Ashe TE, Elter JR, Southerland JH, et al. North Carolina dental hygienists' oral cancer knowledge and opinions: implications for education. J Cancer Educ 2006;21:151-6.

17. Luryi AL, Yarbrough WG, Niccolai LM, et al. Public awareness of head and neck cancers: a cross-sectional survey. JAMA Otolaryngol Head Neck Surg 2014;140:639-46.

18. Brewer NT, Ng TW, McRee A-L, et al. Men's beliefs about HPV-related disease. J Behav Med 2010;33:274-81.

19. Warnakulasuriya KA, Harris CK, Scarrott DM, et al. An alarming lack of public awareness towards oral cancer. Br Dent $J$ 1999;187:319-22.

20. West R, Alkhatib MN, McNeill A, et al. Awareness of mouth cancer in Great Britain. Br Dent J 2006;200:167-9.

21. O'Connor T, Papanikolaou V, Keogh I. Public knowledge of head and neck cancer. Ir Med J 2010;103:105-7.

22. Güneri $P$, Epstein JB. Late stage diagnosis of oral cancer: Components and possible solutions. Oral Oncol 2014;50:1131-6.

23. Passalacqua R, Caminiti C, Salvagni S, et al. Effects of media information on cancer patients' opinions, feelings, decision-making process and physician-patient communication. Cancer 2004;100:1077-84.

24. James C, James N, Davies D, et al. Preferences for different sources of information about cancer. Patient Educ Couns 1999;37:273-82.

25. Metcalfe D, Price C, Powell J. Media coverage and public reaction to a celebrity cancer diagnosis. J Public Health (Oxf) 2011;33:80-5.

26. Lancucki L, Sasieni P, Patnick J. The impact of Jade Goody's diagnosis and death on the NHS Cervical Screening Programme. $J$ Med Screen 2012;19:89-93.

27. Kamenova K, Reshef A, Caulfield T. Angelina Jolie's faulty gene: newspaper coverage of a celebrity's preventive bilateral mastectomy in Canada, the United States, and the United Kingdom. Genet Med 2014;16:522-8.

28. Fishbein M, Yzer M. Using theory to design effective health behavior interventions. Commun Theory 2003;13:164-83.

29. Cancer Research UK. Be Clear on Cancer evaluation update. 2014:1-10. http://www.cancerresearchuk.org/sites/default/files/ evaluation_results_2014.pdf (accessed 9 Nov 2015).

30. Newsworks. Newsbrands 2015. http://www.newsworks.org.uk/ Market-Overview (accessed 9 Nov 2015).

31. Ritchie J, Spencer L. Qualitative data analysis for applied policy research. In: Bryman A, Burgess R, eds. Analysing qualitative data. London: Routledge, 1994:173-94.

32. Quintero Johnson J, Sionean CS, Scott AM. Exploring the presentation of news information about the HPV vaccine: a content analysis of a representative sample of U.S. newspaper articles. Health Commun 2011;26:491-501.

33. Penţa MA, Băban A. Mass media coverage of HPV vaccination in Romania: a content analysis. Health Educ Res 2014;29:977-92.

34. Cohen J. A coefficient of agreement for nominal scales. Educ Psychol Meas 1960;20:37-46.

35. Landis JR, Koch GG. The measurement of observer agreement for categorical data. Biometrics 1977;33:159-74.

36. Kreimer AR, Johansson M, Waterboer $\mathrm{T}$, et al. Evaluation of human papillomavirus antibodies and risk of subsequent head and neck cancer. J Clin Oncol 2013;31:2708-15.

37. Stryker JE, Moriarty CM, Jensen JD. Effects of newspaper coverage on public knowledge about modifiable cancer risks. Health Commun 2008;23:380-90.

38. Dodd RH, Marlow LAV, Waller J. Discussing a diagnosis of human papillomavirus oropharyngeal cancer with patients: An exploratory qualitative study of health professionals. Head Neck 2014;44:1-21.

39. Braun V, Gavey N. Exploring the possibility of sexual-behavioural primary prevention interventions for cervical cancer. Aust $N Z J$ Public Health 1998;22:353-9. 